ORIGINAL ARTICLE

\title{
Overweight and obesity trends from 1974 to 2003 in English children: what is the role of socioeconomic factors?
}

\author{
E Stamatakis, P Primatesta, S Chinn, R Rona, E Falascheti
}

Arch Dis Child 2005;90:999-1004. doi: 10.1136/adc.2004.068932

\begin{abstract}
See end of article for authors' affiliations

Correspondence to:

Dr E Stamatakis,

Department of

Epidemiology and Public Health, University College London, 1-19 Torrington Place, London WC1E 6BT, UK; e.stamatakis@ucl.ac. uk
\end{abstract}

Accepted 7 June 2005 Published Online First 14 June 2005

\begin{abstract}
Aims: To examine the childhood overweight and obesity prevalence trends between 1974 and 2003 and to assess whether these trends relate to parental social class and household income.

Methods: A school based and a general population health survey: the National Study of Health and Growth in 1974, 1984, and 1994, and the Health Survey for England, yearly from 1996 to 2003. Participants were 14587 white boys and 14014 white girls aged 5-10 years. Overweight and obesity prevalence were calculated using UK specific as well as international body mass index $\left(\mathrm{kg} / \mathrm{m}^{2}\right)$ cut-offs. Socioeconomic status was measured using the Registrar General's social class; household income (1997 onwards only) was adjusted for household size.

Results: The prevalence of obesity (UK specific definition) in boys increased from $1.2 \%$ in 1984 to $3.4 \%$ in $1996-97$ and $6.0 \%$ in 2002-03. In girls, obesity increased from $1.8 \%$ in 1984 to $4.5 \%$ in $1996-97$ and $6.6 \%$ in 2002-03. Obesity prevalence has been increasing at accelerating rates in the more recent years. Children from manual social classes had marginally higher odds (OR 1.14,95\% $\mathrm{Cl} 0.98$ to 1.33 ) and children from higher income households had lower odds (OR $0.74,95 \% \mathrm{CI} 0.61$ to 0.89 ) to be obese than their peers from non-manual class, and lower income households, respectively.

Conclusion: Childhood obesity is increasing rapidly into the 2000s in England and these increases are more marked among children from lower socioeconomic strata. There is an urgent need for action to prevent further increase in obesity among children.
\end{abstract}

$\mathrm{D}$ ata from the Health Survey for England ${ }^{2}$ and the Dietary and Nutritional Survey ${ }^{3}$ show that adult overweight and obesity have increased markedly over the last two decades. Despite the use of different methods to define childhood obesity, numerous studies have shown that increases occurred also among British children. ${ }^{4-8}$ This is of great public health concern as excess adiposity at a young age is linked to numerous immediate and long term health risks, including increased risk for asthma and type II diabetes, ${ }^{10}$ persistence of the condition into adulthood, ${ }^{11}{ }^{12}$ and increased middle age mortality and morbidity regardless of adult weight status. ${ }^{13-15}$

Socioeconomic status (SES) has been found to relate to the risk of obesity in adults. ${ }^{16-18}$ Individuals from lower socioeconomic strata may have diets rich in low cost energy dense foods, ${ }^{19}{ }^{20}$ participate less in sports ${ }^{21}$ or physical activity in general, ${ }^{22}$ and have lower weight control awareness. ${ }^{23}$ Lower SES is linked to lower control over one's life and this does not encourages the adoption of healthy lifestyles for a given individual and their children. ${ }^{24}$ However, it is unclear whether parental socioeconomic circumstances affect children's risk for obesity at a young age as highlighted in the review by Sobal and Stunkard ${ }^{25}$ and by other results where SES was found to be inversely related ${ }^{26}{ }^{27}$ or not related ${ }^{28}{ }^{29}$ to childhood obesity in Britain. If a link between parental SES and childhood obesity exists, the new anti-obesity policy initiatives and public health interventions will need to target children from the most vulnerable SES groups.

The aim of this study is to provide an update on the most recent prevalence trends of overweight and obesity among British children and to investigate the role of parental SES in the risk for developing the condition. Anthropometric data from the 1970s provided the opportunity to examine whether obesity changed at different rates for children from different social class backgrounds. Our hypothesis was that overweight and obesity prevalence have been increasing at a faster rate among children from lower SES groups.

\section{METHODOLOGY \\ Participants}

Data for this study come from 28601 children aged 5-10 years participating in two health surveys: the National Study of Health and Growth (NSHG) in 1974, 1984, and 1994, and the Health Survey for England (HSE) from 1996 to 2003 (yearly). The NSHG sample was selected via state primary schools in England and Scotland. ${ }^{4}$ In this analysis we included only English children. NSHG areas were selected by stratified random sampling and schools were then selected within these areas. In most years around $95 \%$ of children ${ }^{30}$ in included schools were measured for height and weight. The Health Survey for England draws every year a representative sample of the general population using multi-stage stratified probability sampling, with postcode sectors as primary sampling units and the Postcode Address File as the sampling frame for households. Interviewer response rates for children in HSE varied between $75 \%$ and $85 \%$, depending on the survey year. Among cooperating households, height and weight measurements were obtained from around $90-95 \%$ of eligible children, depending on the survey year. Both surveys had relatively low numbers of non-white children, so only white children were included in this analysis.

\section{Ethical approval}

Ethical approval had been granted by the London Medical Research Ethics Council and/or local research ethics councils prior to each annual data collection cycle of the HSE. When the NSHG began in 1972 a system of ethical committees for community based studies had not been established, but the 


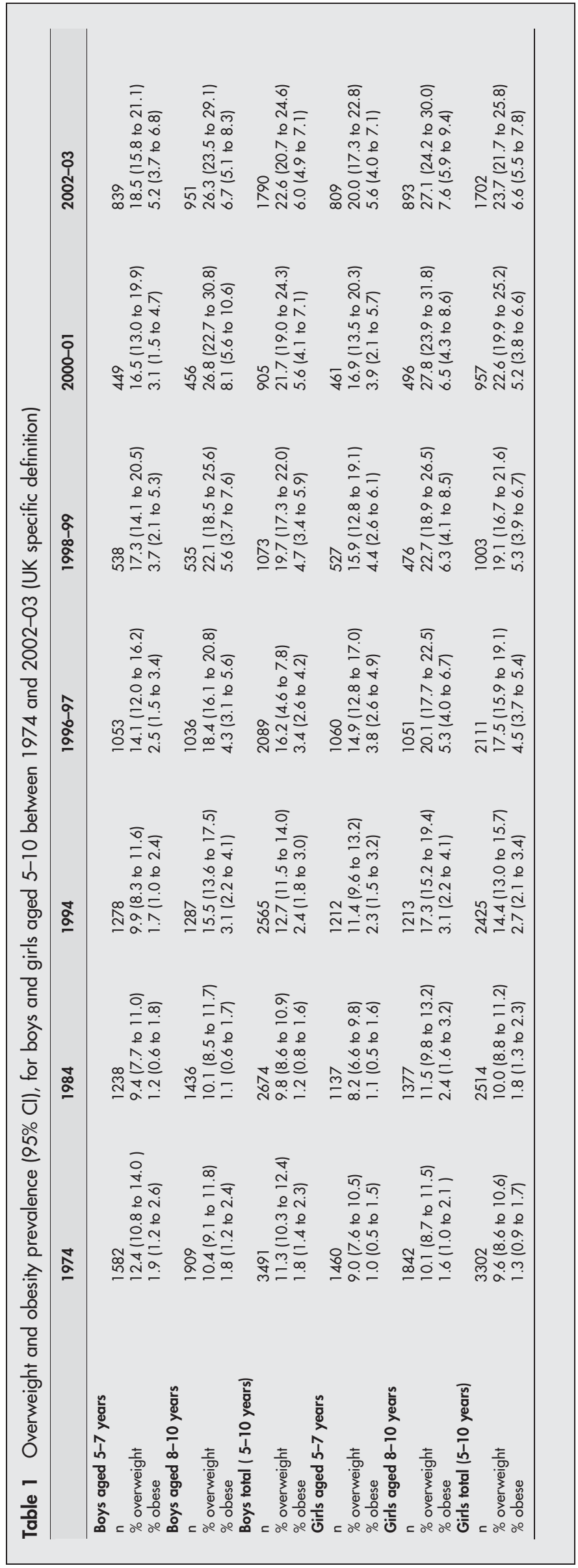

coordinators at the time obtained ethical approval from St Thomas' Hospital Medical Ethics Committee. Participation of schools was agreed with the health and education authorities in each selected area, and with the head teacher. Parents were notified of the study in advance and were able to withdraw their child from measurement.

\section{Physical measurements}

Exact age was used to calculate prevalence rates but age was rounded to the nearest integer and grouped for the presentation of the results. Height and weight in the NSHG and the HSE were measured by a school nurse and an interviewer, respectively, using the same standard protocols. The NSHG used Holtain (Holtain, Crymych, Dyfed, UK), and the HSE used Chasmors (Chasmors Ltd, London, UK) stadiometers to measure height. In all HSE years and 1994 NSHG weight was measured by electronic digital scales (beam balances were used by the NSHG in 1974 and 1984). Children were weighed wearing only underpants in the NSHG, while in the HSE informants were asked to remove only shoes, accessories, and heavy clothing items. Children's weights in HSE have been adjusted for clothing, ${ }^{31}$ giving estimated unclothed weights comparable with those of NSHG.

\section{Socioeconomic status measures}

The occupation of the head of the household determined children's social class. In HSE this information was collected during the interviews with the head of the household. In the NSHG this information was collected by parental self-competed questionnaires that were taken home by the child or posted, and returned in a closed envelope by the child or posted. We used the Registrar-General's classification in this report. Household income (adjusted for household size) was available for HSE years from 1997 onwards. Income information was also collected during the interviews with the children's parents. Income information was available for NSHG 1974 but it was not possible to categorise it in the same way as in the HSE as it was reported in broad categories.

\section{Overweight and obesity measures}

Body mass index (BMI) was calculated as weight (kg) divided by squared height $\left(\mathrm{m}^{2}\right)$. Overweight and obesity rates were computed using a set of age and sex specific BMI cut-off points ${ }^{32}$ based on the UK 1990 BMI reference data. ${ }^{33}$ These BMI cut-off points were developed using the same method as the international BMI cut-offs ${ }^{34}$ but used UK specific data and correspond to the adult BMI cut-offs of 25 and $30 \mathrm{~kg} / \mathrm{m}^{2}$ at age 19.5 (as opposed to the international standards which are based on the averaged and smoothed BMI curves of six countries and correspond to the adult BMI cut-offs at age 18). Confirmatory analyses of the overweight and obesity prevalence trends were performed using international standards.

\section{Statistical analysis}

HSE years were merged in pairs (1996-97; 1998-99; $2000-01 ; 2002-03)$ to increase statistical power at each time point. We computed the sex and age specific (5-7 years and 8-10 years) prevalence of overweight (including obesity) and obesity at each time point between 1974 and 2002-03 for the entire population, and by social class. Social classes based on occupations are unstable over time in relation to each social class but 


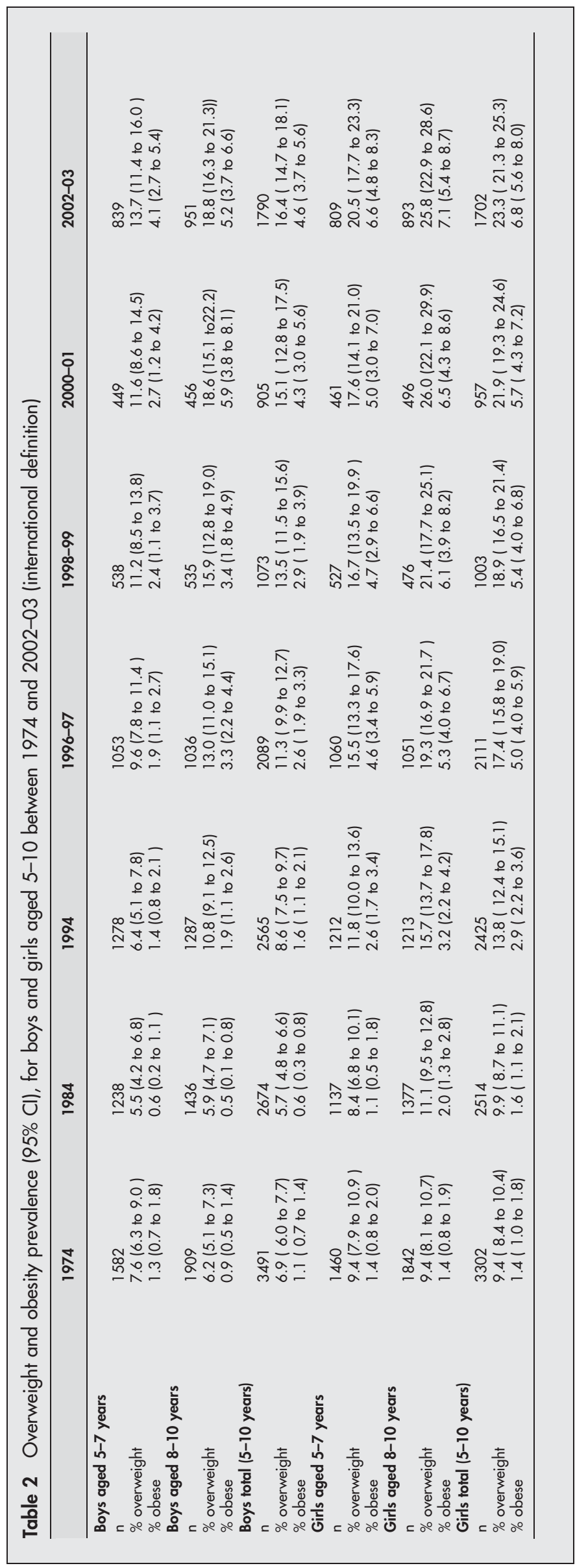

stable over time in relation to the non-manual and manual contrast: the classification of occupations is modified every 10 years before the census. Some occupations disappear over time, others are newly created, and others decrease or increase status according to new technology. Thus each social class includes a different but overlapping set of units of occupations. In contrast, it is less likely that an occupation will be reclassified from manual to non-manual or vice versa. For this reason, social class was dichotomised into nonmanual (I, II, IIINM) and manual (IIIM, IV, V). Since household income data were not available for all years, prevalence trends by income were examined between 1997, 1998-99, 2000-2001, and 2002-03. For this analysis we compared the bottom 50\% (lower income group) with the top $50 \%$ (higher income group) of the income distribution, using the internal 50th centile as a cut-off for each HSE year. The relation of overweight and obesity with time point, sex, age group, and social class were tested by multiple logistic regression where obesity or overweight were the binary dependent variables. The effect of social class on the prevalence trend was tested by examining both the linear and quadratic interactions between social class and time point. We also examined the linear and quadratic interactions between time point and sex, and time point and age group. As income data were only available from 1997 onwards, we ran a separate logistic regression model to examine the relation between overweight and obesity with income and time point, and the linear and quadratic interactions of income with time point.

\section{RESULTS}

A total of 14587 boys and 14014 girls had a valid BMI. Of those, $87 \%$ of both boys $(n=12692)$ and girls $(\mathrm{n}=12178)$ had valid parental occupation information and were included in the analysis by social class. Analyses by income included 4729 boys and 4698 girls measured in 1997 or later with a valid BMI and valid household income information. There were no significant differences in sex distribution, mean age, or mean BMI between those with valid BMI and the sub-samples with valid SES indicators that were included in the analyses.

Table 1 presents the overweight and obesity prevalence rates by sex, age group, and survey year(s). While no or little change in the prevalence of overweight and obesity was seen over the period 1974-84 in either sex, the increase since 1984 has been more marked, especially from 1994 onwards. Overall, the prevalence of obesity in boys increased from $1.2 \%$ in 1984 to $3.4 \%$ in 1996-97 and 6.0\% in 2002-03. In girls, obesity increased from $1.8 \%$ in 1984 to $4.5 \%$ in $1996-97$ and $6.6 \%$ in $2002-$ 03. Repeating the same analysis using the international classification standards did not change the upward trend but, as previously reported, ${ }^{45}$ increased the differences between boys and girls which were statistically significant at all time points. Table 2 presents the overweight and obesity prevalence trends over the same time period using the international classification standards.

Increases in both overweight and obesity prevalence rates were significantly different from 1974 to 1984 onwards, as shown by the odds ratios and 95\% confidence intervals presented in table 3. Children's odds to be overweight in 2002-03 were over two and a half times higher than in 1974 and the odds to be obese in 2002-03 were over four times higher than in 1974. Children aged 8-10 had significantly higher odds to be 
Table 3 Mutually adjusted odds ratios and $95 \%$ confidence intervals for overweight and obesity for time point, social class, sex, and income group

\begin{tabular}{|c|c|c|c|c|c|c|c|}
\hline & \multirow[b]{3}{*}{$\mathbf{n}$} & \multicolumn{3}{|l|}{ Overweight } & \multicolumn{3}{|l|}{ Obesity } \\
\hline & & \multirow[b]{2}{*}{ OR } & \multicolumn{2}{|l|}{$95 \% \mathrm{Cl}$} & \multirow[b]{2}{*}{ OR } & \multicolumn{2}{|l|}{$95 \% \mathrm{Cl}$} \\
\hline & & & Lower & Upper & & Lower & Upper \\
\hline Year & & \multicolumn{3}{|l|}{$(p<0.001)$} & \multicolumn{3}{|l|}{$(p<0.001)$} \\
\hline $1974^{*}$ & 5595 & 1 & - & - & 1 & - & - \\
\hline 1984 & 4171 & 1.02 & 0.89 & 1.17 & 1.02 & 0.73 & 1.42 \\
\hline 1994 & 3919 & 1.44 & 1.27 & 1.64 & 1.77 & 1.31 & 2.39 \\
\hline 1996-97 & 4018 & 1.80 & 1.59 & 2.04 & 2.62 & 1.99 & 3.46 \\
\hline 1998-99 & 2013 & 2.13 & 1.85 & 2.46 & 3.37 & 2.49 & 4.56 \\
\hline 2000-01 & 1782 & 2.54 & 2.20 & 2.93 & 3.65 & 2.68 & 4.95 \\
\hline $2002-03$ & 3372 & 2.67 & 2.36 & 3.01 & 4.25 & 3.25 & 5.55 \\
\hline Social class & & \multicolumn{3}{|l|}{$(p=0.133)$} & \multicolumn{3}{|l|}{$(p=0.080)$} \\
\hline Non-manual* & 11299 & 1 & - & - & 1 & - & - \\
\hline Manual & 13571 & 1.05 & 0.98 & 1.13 & 1.14 & 0.98 & 1.33 \\
\hline Sex & & \multicolumn{3}{|l|}{$(p=0.310)$} & \multicolumn{3}{|l|}{$(p=0.047)$} \\
\hline Boys* & 12692 & 1 & - & - & 1 & - & - \\
\hline Girls & 12178 & 1.04 & 0.97 & 1.11 & 1.15 & 1.00 & 1.32 \\
\hline Age group & & \multicolumn{3}{|l|}{$(p<0.001)$} & \multicolumn{3}{|l|}{$(p<0.001)$} \\
\hline $5-7$ years* & 11829 & 1 & - & - & & - & - \\
\hline $8-10$ years & 13041 & 1.39 & 1.30 & 1.49 & 1.49 & 1.29 & 1.72 \\
\hline Household income $\ddagger$ & & \multicolumn{3}{|l|}{$(p=0.466)$} & \multicolumn{3}{|l|}{$(p=0.002)$} \\
\hline Lower* & 4729 & 1 & - & - & & - & - \\
\hline Higher & 4698 & 0.96 & 0.87 & 1.07 & 0.74 & 0.61 & 0.89 \\
\hline $\begin{array}{l}\text { *Reference category. } \\
\text { +Lower: up to the } 50 \text { th } \\
\text { Ilncome category odd } \\
2000-01 \text {, and } 2002-\end{array}$ & $\begin{array}{l}\text {; highe } \\
\text { calculat }\end{array}$ & er the 50 th & $\begin{array}{l}\text { tile. } \\
\text { istic re }\end{array}$ & ssion & el using $d c$ & m 19 & $1998-9$ \\
\hline
\end{tabular}

overweight and obese than children aged 5-7. Both sex and social class showed associations with obesity prevalence that were of borderline statistical significance: girls' odds to be obese were higher than boys' (OR 1.15, 95\% CI 1.00 to 1.32 , $\mathrm{p}=0.05)$, and children from manual classes had higher odds than children from non-manual classes (OR 1.14, 95\% CI 0.98 to $1.33, p=0.08$ ). The interactions between time point and social class, and time point and sex were not significant. The interaction between age group and time point was significant for the prevalence of overweight (but not obesity), with children aged 8-10 showing significantly faster rates of increase than children aged $5-7(p<0.001)$. Although the interaction of income group and time was not significant, the odds for obesity were significantly higher among children from lower income households than among children from higher income households (table 3 and fig 1).

All logistic regression analyses were repeated using the international BMI classification standards ${ }^{34}$ to calculate overweight and obesity prevalence. As expected, sex was significantly associated with both overweight and obesity

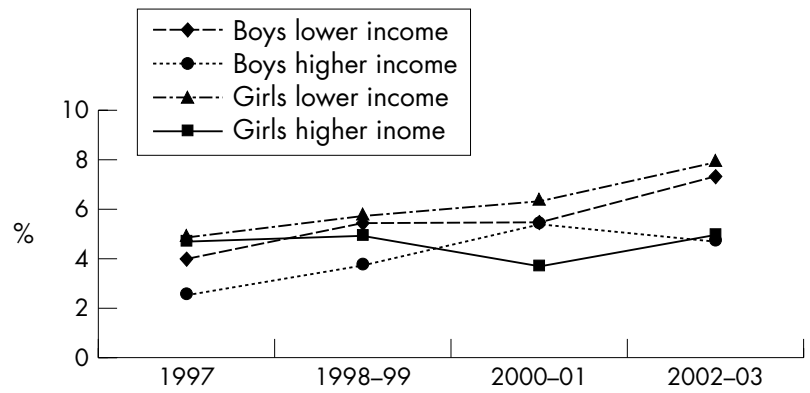

Figure 1 Obesity prevalence trends from 1997 to 2002-03 by income category and sex. Lower income: bottom 50\% of income distribution of each individual year; higher income: top 50\% of income distribution of each individual year. prevalence, with the odds being higher among girls $(\mathrm{p}<0.0001)$. However, all other results were similar to those obtained using the National BMI cut-offs (data not shown).

\section{DISCUSSION}

These results showed that the upward trends in overweight and obesity in children noted by other authors ${ }^{4-7}$ over the 1990 s are continuing into the 2000s and, more alarmingly, that the rate of increase has accelerated over the last decade. Evidence for an accelerated trend for children of a similar age (7-11 years) was first reported by Lobstein and colleagues ${ }^{5}$ using HSE 1998 data and comparing them with already published NSHG figures from 1974, 1984, and 1994. In our study, the obesity prevalence change for boys was an average increase of 0.03 percentage points per annum (pppa) for the period 1974-94 and of 0.44 pppa for the period 1996-97 to 2002-03. For girls, the average annual rate increased from 0.07 pppa for the period 1974-94 to 0.35 pppa for the period 1996-97 to 2002-03. These figures represent a 15-fold and 5fold increase in the average annual rates of change for boys and girls, respectively. Our results show that a recently publicised report, ${ }^{36}$ that was based on mean BMI and mean weight trends, was misleading in claiming that there is no increase in childhood obesity in England. Our data show that the sharp upward trend is independent of the obesity definition used as both the UK specific and the international definitions confirmed this.

Other studies have shown that while family social class at birth $^{37}$ and in infancy ${ }^{38}$ have a long term effect on BMI, the relation seems to be less clear during childhood and adolescence. ${ }^{39}$ We showed an association of borderline significance between parental social class and obesity among this population of 5-10 year olds, but a rapid upward overall trend in recent years, especially among children from lower income households, as shown in fig 1. Regardless of the differences in the magnitude of the correlations, the overall results for social class parallel those for income as shown in 


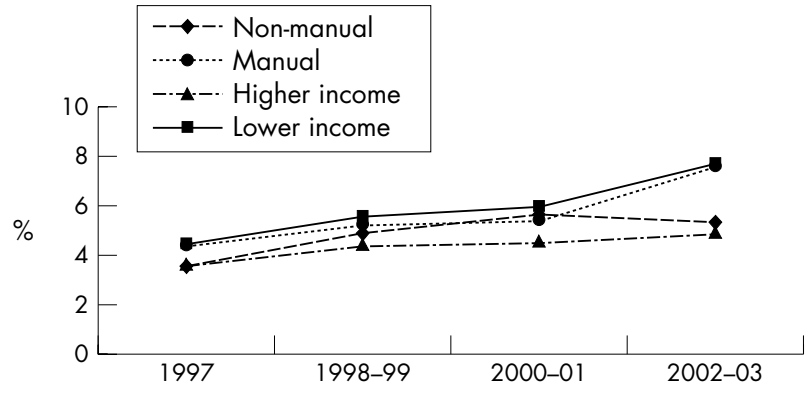

Figure 2 Obesity prevalence trends from 1997 to 2002-03 by income group and social class for boys and girls combined. Lower income: bottom $50 \%$ of income distribution of each individual year; higher income: top $50 \%$ of income distribution of each individual year.

fig 2. Obesity among children from manual classes and children from lower income households seems to be increasing more rapidly than among children from nonmanual classes and higher income households, respectively. This similarity in trends is not explained by the intercorrelation between income and social class variables as the correlation coefficient was of moderate to low magnitude only (Spearman's rho $=0.37$ ) and their interaction was nonsignificant. These results suggest that both material deprivation and other early social influences such as parental occupation are closely related to the development of obesity in childhood. In the case of income, it may be that the availability of healthy food is a mediator, since financial constraints may be the main obstacle with regard to access to a healthy diet. ${ }^{20}{ }^{40}$ The different magnitude of the relations between obesity prevalence and the two SES indicators suggests that income may be a more sensitive indicator of socioeconomic status than social class. Income based indices have been previously found to outperform occupation based ones in predicting health related outcomes. ${ }^{41}$

One of the limitations of this study is that the slightly different methodologies and sampling procedures between HSE and NSHG may partly account for the differences observed over time, and especially the sharp increase in prevalence between 1994 (last NSHG point) and 1996-97 (first HSE point). However, these increases continued the upward trend already found between the mid-1980s and the mid-1990s in the NSHG. Another limitation of this study lies in the reliance on BMI to calculate overweight and obesity: although BMI's components are highly repeatable in survey conditions, BMI is a poor proxy measure of obesity in childhood $^{42}{ }^{43}$ as it does not measure fat directly. This may provide an explanation for the constant overweight and obesity prevalence from 1974 to 1984 and the relatively small increases between 1984 and 1994, when visually children were clearly getting fatter. This can been attributed to the failure of BMI to detect a shift from muscle to fat over the period, as children may have became both fatter and probably less active since weight was relatively unaffected. ${ }^{44} 45$

These data suggested that social class and especially income inequalities should be tackled, and interventions aimed at relieving economic hardship may reduce the risk of behaviours damaging health from childhood. The World Health Organisation' ${ }^{40}$ general recommendations to combat childhood obesity include the promotion of active lifestyles, the restriction of television viewing, the promotion of fruit and vegetable consumption, and the restriction of energy dense and sugary foods and drinks. Future research should provide more information on the effectiveness of specific public health interventions to combat childhood obesity in Britain and on the mechanisms of how lower income and social class may influence obesity among children.
What is already known on this topic

- Childhood obesity in England increased through the 1980s and 1990s

- The role of parental socioeconomic status in childhood obesity is unclear

\section{What this study adds}

- Childhood obesity prevalence is increasing at accelerating rates through the 2000 s

- Obesity increases are more pronounced among boys and girls from lower income and manual occupation households

In conclusion, this is the first study to our knowledge to report on the long term and most recent overweight and obesity prevalence trends using both UK specific and international obesity classification standards, as well as multiple SES indicators. Obesity rates among both boys and girls increased at accelerating rates into the early 2000s and these upward trends were more marked among children from lower income families and to a lesser extent among children from manual social classes. Considering the calamitous consequences of obesity, there is an urgent need for action to halt and reverse this rapid upward trend among English children, especially among those from lower socioeconomic strata.

\section{ACKNOWLEDGEMENTS}

The Health Survey for England is carried out by the Joint Health Surveys Unit (University College London and the National Centre for Social Research).

\section{Authors' affiliations}

E Stamatakis, P Primatesta, E Falascheti, University College, London, UK

S Chinn, R Rona, King's College, London, UK

Funding: The Health Survey for England and the National Study of Health and Growth were both funded by the Department of Health. None of the authors of this paper has been an employee of the funding bodies

Competing interests: none

\section{REFERENCES}

1 White A, Nicolaas G, Foster K, et al. Health Survey for England 1991. Anthropometric Measurements. London: The Stationery Office, 1993.

2 Hirani V. Anthropometric measures, overweight, and obesity. In: Sporston K, Primatesta P, eds. The Health Survey for England 2003, Cardiovascular Disease. London: The Stationery Office, 2004.

3 Gregory J, Foster K, Tyler H, et al. The Dietary and Nutritional Survey of British Adults. London: The Stationery Office, 1990

4 Chinn S, Rona RJ. Prevalence and trends in overweight and obesity in three cross sectional studies of British children, 1974-94. BMJ 2001;322:24-6.

5 Lobstein TJ, James WPT, Cole TJ. Increasing levels of excess weight among children in England. Int J Obes 2003;27:1136-8.

6 Reilly J, Dorosty A, Emmett P. Prevalence of overweight and obesity in British children: cohort study. BMJ 1999;319:1039.

7 Bundred P, Kitciner D, Buchan I. Prevalence of overweight and obese children between 1989 and 1998: population based series of cross sectional studies. BMJ 2001;322:1-4.

8 Rudolf MCJ, Sahota P, Barth JH, et al. Increasing prevalence of obesity in primary school children: cohort study. BMJ 2001;322:1094-5.

9 Von Mutius E, Schwartz J, Neas LM, et al. Relation of body mass index to asthma and atopy in children: the National Health and Nutrition Examination Study III. Thorax 2001;56:835-8. 
10 Fagot-Campagna A, Pettitt DJ, Engelgau MM, et al. Type 2 diabetes among North American children and adolescents: an epidemiologic review and a public health perspective. J Pediatr 2000;136:664-72.

11 Kvaavik E, Tell GS, Klepp KI. Predictors and tracking of body mass index from adolescence into adulthood. Follow-up of 18 to 20 years in the Oslo Youth Study. Arch Pediatr Adolesc Med 2003;157:1212-18.

12 Guo SS, Chumlea W. Tracking of body mass index in children in relation to overweight in adulthood. Am J Clin Nutr 2000;70(suppl):145S-148S.

13 Gunnell D, Frankel S, Nanchahal K, et al. Childhood obesity and adult cardiovascular mortality: a 57-y follow-up study based on the Boyd Orr cohort. Am J Clin Nutr 1998;67:1 111 1-18

14 Must A, Jacques PF, Dallal GE, et al. Long-term morbidity and mortality of overweight adolescents - a follow-up of the Harvard growth study of 1922 to 1935. N Engl J Med 1992;327:1350-5

15 Engeland A, Bjorge T, Sogaard AJ, et al. Body mass index in adolescence in relation to total mortality: 32-year follow-up of 227,000 Norwegian boys and girls. Am J Epidemiol 2003; 157:517-23.

16 Ball K, Mishra G, Crawford D. Which aspects of socioeconomic status are related to obesity among men and women? Int J Obes 2002;26:559-65.

17 Molarius A. The contribution of lifestyle factors to socioeconomic differences in obesity in men and women-a population-based study in Sweden. Eur J Epidemiol 2003;18:227-34.

18 Wardle J, Waller J, Jarvis MJ. Sex differences in the association of socioeconomic status with obesity. Am J Public Health 2002;92:1299-304.

19 Lu N, Samuels ME, Huang KC. Dietary behavior in relation to socioeconomic characteristics and self-perceived health status. J Health Care Poor Underserved 2002;13:241-57.

20 Drewnowski A, Specter SE. Poverty and obesity: the role of energy density and energy costs. Am J Clin Nutr 2004;79:6-16.

21 Stamatakis E. Physical activity. In: Sporston K, Primatesta P, eds. The Health Survey for England 2003, Cardiovascular Disease. London: The Stationery Office, 2004.

22 Winkleby MA, Kraemer HC, Ahn DK, et al. Ethnic and socioeconomic differences in cardiovascular disease risk factors: findings for women from the Third National Health and Nutrition Examination Survey, 1988-1994. JAMA 1998;280:356-62.

23 Wardle J, Griffith J. Socioeconomic status and weight control practices in British adults. J Epidemiol Community Health 2001;55:185-90.

24 Mirowsky J, Ross CE. Education, personal control, lifestyle and health-a human capital hypothesis. Research on Aging 1998;20:415-49.

25 Sobal J, Stunkard AJ. Socioeconomic-status and obesity-a review of the literature. Psychol Bull 1989;105:260-75.

26 Jebb SA, Rennie KL, Cole TJ. Prevalence of overweight and obesity among young people in Great Britain. Public Health Nutr 2004;7:461-5.

27 Kinra S, Nelder RP, Lewenson GJ. Deprivation and childhood obesity: a cross sectional study of 20,973 children in Plymouth, United Kingdom. J Epidemiol Community Health 2000;54:456-60.
28 Saxena S, Ambler G, Cole TJ, et al. Ethnic group differences in overweight and obese children and young people in England: cross sectional survey. Arch Dis Child 2004;89:30-6

29 Duran-Tauleria E, Rona RJ, Chinn S. Factors associated with weight for height and skinfold thickness in British children. J Epidemiol Community Health 1995;49:466-73

30 Chinn S. Monitoring the growth of children: conclusions from a long-term study. Int J Epidemiol 1995:24:569-77.

31 Cameron N. The growth of London schoolchildren 1904-1966: an analysis of secular trend and intra-county variation. Ann Hum Biol 1979;6:505-25.

32 Chinn S, Rona RJ. Letter to the editor re: International definitions of overweight and obesity for children: a lasting solution? Ann Hum Biol 2004;31:695-6.

33 Cole TJ, Freeman JV, Preece MA. British 1990 growth reference centiles for weight, height, body mass index and head circumference fitted by maximum penalised likelihood. Stat Med 1998;17:407-29.

34 Cole T, Bellizzi M, Flegal K, et al. Establishing a standard definition for child overweight and obesity worldwide: an international survey. BMJ 2000;320: 1-6.

35 Chinn S, Rona RJ. International definitions of overweight and obesity for children: a lasting solution? Ann Hum Biol 2002;29:306-13.

36 Social Issues Research Centre. Obesity and the facts: an analysis of data from the Health Survey for England 2003. Oxford: Social Issues Research Centre, 2005.

37 Laitinen J, Power C, Jarvelin MR. Family social class, maternal body mass index, childhood body mass index, and age at menarche as predictors of adult obesity. Am J Clin Nutr $2001 ; 74: 287-94$.

38 Langenberg C, Hardy R, Kuh D, et al. Central and total obesity in middle aged men and women in relation to lifetime socioeconomic status: evidence from a national birth cohort. J Epidemiol Community Health 2003;57:816-22

39 Okasha M, McCarron P, McEwen J, et al. Childhood social class and adult obesity: findings from the Glasgow Alumni Cohort. J Epidemiol Community Health 2003;57:508-9.

40 World Heath Organisation. Technical Report Series 916. Diet, nutrition and the prevention of chronic diseases. Report of a Joint WHO/FAO Expert Consultation. Geneva: World Heath Organisation, 2003.

41 Chandola T. Social class differences in mortality using the new UK National Statistics Socio-Economic Classification. Soc Sci Med 2000;50:641-9.

42 Prentice AM, Jebb SA. Beyond body mass index. Obesity Reviews 2001;2:141-7.

43 Wells JCK. A Hattori chart analysis of body mass index in infants and children. Int J Obes 2000;24:325-9.

44 Chinn S, Rona RJ. Trends in weight-for-height and triceps skinfold thickness for English and Scottish children, 1972-1982 and 1982-1990. Paediatr Perinat Epidemiol 1994;8:90-106.

45 Hughes JM, Li L, Chinn S, et al. Trends in growth in England and Scotland, 1972 to 1994. Arch Dis Child 1997;76:182-9. 